\title{
Ionic Liquid-based Microwave-Assisted Extraction (Il-MAE) of Oxyresveratrol from Morus alba Roots
}

\author{
Mazaya Fadhila', Abdul Mun'im ${ }^{1,2}$, Mahdi Jufri ${ }^{1 *}$ \\ ${ }^{1}$ Graduate Programme of Herbal Medicine, Faculty of Pharmacy, Universitas Indonesia, Depok 16424, West Java, Indonesia. \\ ${ }^{2}$ Department of Pharmacognosy-Phytochemistry, Faculty of Pharmacy, Universitas Indonesia, Depok 16424, West Java, Indonesia.
}

\begin{tabular}{|c|c|}
\hline ARTICLE INFO & ABSTRACT \\
\hline $\begin{array}{l}\text { Article history: } \\
\text { Received on: } 15 / 02 / 2018 \\
\text { Accepted on: } 14 / 05 / 2018 \\
\text { Available online: } 29 / 06 / 2018\end{array}$ & $\begin{array}{l}\text { The objective of this study was to investigate the efficacy of using ionic liquid-based microwave-assisted (IL-MAE) } \\
\text { approach for extraction of oxyresveratrol from Morus alba roots and to compare the result with conventional extraction. } \\
\text { The roots were extracted with nine IL, 1-butyl-3-methylimidazolium chloride }(\mathrm{BmimCl}), 1 \text {-butyl-3-methylimidazolium } \\
\text { bromide }(\mathrm{BmimBr}) \text {, or 1-butyl-3-methylimidazolium tetrafluoroborate }\left(\mathrm{BmimBF}_{4}\right) \text { at concentration } 1.5,1.67 \text {, and } 2 \\
\mathrm{M} \text { for each IL, in a microwave at Power } 30 \% \text { for } 10 \text { minutes respectively. The extracts were filtrated and diluted with }\end{array}$ \\
\hline $\begin{array}{l}\text { Key words: } \\
\text { ionic liquid, oxyresveratrol, } \\
\text { Morus alba, ionic liquid- } \\
\text { based microwave-assisted } \\
\text { extraction. }\end{array}$ & $\begin{array}{l}30 \mathrm{ml} \text { of deionized water. Then, fractionated with ethyl acetate and salting out by addition of } \mathrm{Na}_{2} \mathrm{CO}_{3} \text { or } \mathrm{KH}_{2} \mathrm{PO}_{4} \text {. } \\
\text { The fractions were analyzed for oxyresveratrol contents with TLC-densitometer and HPLC. Then the result was } \\
\text { compared with conventional methods. IL-MAE approach showed improvement extraction efficiency compared to } \\
\text { the conventional ethanol and methanol macerations. The optimized solvent condition for extraction of oxyresveratrol } \\
\text { from Morus alba root was } 1.5 \mathrm{M} \mathrm{BmimCl} \mathrm{with} 0.01 \mathrm{M} \mathrm{KH}_{2} \mathrm{PO}_{4} \text { salt. Oxyresveratrol was separated by ethyl acetate } \\
\text { fractionation, and the yield calculated was } 3.53 \% \text { from raw material. The study showed that IL-MAE was an efficient } \\
\text { method for the extraction of oxyresveratrol from Morus alba roots. }\end{array}$ \\
\hline
\end{tabular}

\section{INTRODUCTION}

White mulberries (Morus alba) roots have been used since a long time ago as Chinese traditional medicine to cure inflammation diseases. The root of this plant contains terpenoids, flavonoids, and stilbene, including oxyresveratrol and resveratrol (Chan et al., 2016). Oxyresveratrol has been known to inhibit mushroom tyrosinase activities with $\mathrm{IC}_{50}$ value of $1.2 \mu \mathrm{M}$ (Kim et al., 2002), was 32 times stronger than that kojic acid (Shin et al., 1998). Ionic liquids (IL) are a group of non-molecular compounds, with a melting point below $100^{\circ} \mathrm{C}$. Typically, they consist of big, asymmetric organic cation (e.g., imidazolium, pyrrolidinium, or pyridinium) and smaller organic or inorganic anion (e.g., tetrafluoroborate, bromide) (Justyna et al., 2017). IL has been applied in an analysis, organic synthesis, and separation technic because it has good physical and chemical properties, including

\footnotetext{
${ }^{*}$ Corresponding Author

Mahdi Jufri, Faculty of Pharmacy, Universitas Indonesia, Depok 16424, West Java, Indonesia.

E-mail:mahdi.jufri@farmasi.ui.ac.id; mazaya.fadhila@ui.ac.id
}

unvaporized, good stability, viscosity, solubility, and extraction ability to different organic compounds and easy to be controlled, if was compared to conventional solvents. Microwave-assisted Extraction (MAE) is a fast and easy sample preparation technique. IL is potentially applied as MAE solvent for various compounds from the crude sample because IL can absorb efficiently the microwave energy (Han and Row, 2010). IL interacts efficiently with microwave through the ionic conduction mechanism and rapidly heated without any significant pressure build-up. Therefore, safety concerns arising from over pressurization of heated sealed reaction vessels can be minimized (Vekariya, 2017). Recently, IL 1-n-butyl-3-methylimidazolium has been investigated as a solvent in the extraction of trans-resveratrol from Polygonum cuspidatum roots, that shows IL is potentially applied to MAE for some compound from the medicinal plant (Du et al., 2007). Until now, there is no report about extraction of oxyresveratrol using ionic liquid. Therefore, this study aimed to investigate the effect ionic liquid-based microwave assisted extraction to increase oxyresveratrol yield of Morus alba and to compare this method with conventional extraction methods on literature. 


\section{MATERIAL AND METHODS}

\section{Samples}

The roots of Morus alba were collected from Rumah Sutera, Bogor and has been identified in Research Center for Biology LIPI Bogor. The roots were washed with water, then air dried for six days at room temperature and protected from sunlight, and then ground.

\section{Chemicals}

The ILs, 1-butyl-3-methylimidazolium chloride (BmimCl), 1-butyl-3-methylimidazolium bromide (BmimBr) and 1-butyl-3-methylimidazolium tetrafluoroborate $\left(\mathrm{BmimBF}_{4}\right)$ were purchased from Shanghai Chengjie Chemical Co. Ltd., China. Standard trans-oxyresveratrol was purchased from Shanghai Yuanye Bio-Technology Co., Ltd. Deionized water, ethanol, methanol, chloroform, acetic acid, ethyl acetate, acetonitrile, $\mathrm{Na}_{2} \mathrm{CO}_{3}, \mathrm{KH}_{2} \mathrm{PO}_{4}$ were obtained from the local supplier. The extraction method used the microwave (Modena MV 3002 900Watt), The analytical method used TLC silica gel $60 \mathrm{~F}_{254}$ with TLC scanner III Camag CATs system (Muttenz, Switzerland), and HPLC system (LC-20AT, Shimadzu, Kyoto, Japan).

\section{Extraction IL-MAE}

Nine Ionic Liquids (ILs) were prepared by diluting each

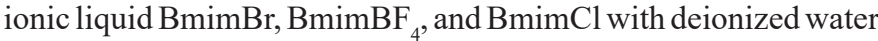
$100 \mathrm{ml}$ to make concentration $1.5,1.67$, and $2 \mathrm{M}$, respectively. $M$. alba root powder ( $1 \mathrm{~g}$ ) was dissolved in $20 \mathrm{ml}$ ionic liquid solution in a flask for each concentration, then put into the microwave. The microwave set at $30 \%$ power (900-watt microwave) and run for 10 minutes. The suspension was filtered through filter paper and diluted ad $30 \mathrm{ml}$ with deionized water. Each IL extraction was repeated three times and collected (Du et al., 2007).

\section{Ethyl acetate fractionation and separation of IL with salt}

The separation of IL from the extracts was optimized by using $\mathrm{Na}_{2} \mathrm{CO}_{3}$ or $\mathrm{KH}_{2} \mathrm{PO}_{4}$ salts at different concentrations $(0.01,0.1,0.5$, and $1 \mathrm{M}$ respectively). The IL extracts then were fractionated by ethyl acetate (EA). $1 \mathrm{ml}$ IL-MAE extracts added with $1 \mathrm{ml}$ salt of $\mathrm{Na}_{2} \mathrm{CO}_{3}$ or $\mathrm{KH}_{2} \mathrm{PO}_{4}$ and fractionated with $1 \mathrm{ml}$ EA. The solution was vortexed for 10 seconds, then centrifuged for 10 minutes at $3000 \mathrm{rpm}$. Two phases of solution appeared, and the upper layer (EA fraction) was taken for further analysis (Ayuningtyas et al., 2017). For comparison, the same procedure was repeated for separation without salt.

\section{Thin layer chromatography (TLC) analysis}

Standard trans-oxyresveratrol solution was prepared at concentration $1 \mathrm{mg} / \mathrm{ml}$ with $80 \%$ ethanol. TLC analysis was performed using silica gel $60 \mathrm{~F}_{254}$ (Merck, Darmstadt, Germany) as a stationary phase and methanol:chloroform:acetate acid $(10: 88: 2 \% \mathrm{v} / \mathrm{v})$ as a mobile phase. The samples were EA fractions (with salt and without salt) and standard. Samples were spotted 5 $\mu \mathrm{l}$ and then were placed in the chamber that was saturated with solvent before. After that, the plate was removed from the chamber and air-dried. The TLC spots were viewed under UV light at 366 nm wavelength (Soonthornsit et al., 2017), and were analyzed by densitometry TLC scanner with detector $254 \mathrm{~nm}$ wavelength to give area under curve (AUC) values of trans-oxyresveratrol. EA fraction with highest AUC value then chose to continue as the pilot scale of extraction and analyzed by HPLC.

\section{Pilot-scale of IL-MAE}

The optimum IL and salting out extractions condition with highest AUC value was studied further to calculate transoxyresveratrol yield. 10 grams of root powder was added $200 \mathrm{ml}$ IL solution, then was microwaved, filtered and added $300 \mathrm{ml}$ of deionized water. The solution was added $300 \mathrm{ml}$ salt and $300 \mathrm{ml}$ ethyl acetate and was mixed at $1000 \mathrm{rpm}$ for 10 minutes with a magnetic stirrer. The solution was centrifuged at $3000 \mathrm{rpm}$ for $10 \mathrm{~min}$ to separate EA fraction. This procedure was repeated four times with fresh EA. The EA fractions then were collected and evaporated in vacuum rotary evaporator and the yield calculated as below:

$$
\% \text { yield }=\frac{\text { ethyl acetate fraction mass }}{\text { crude sampel mass }} \times 100 \%
$$

\section{High-performance liquid chromatography (HPLC) analysis of oxyresveratrol in the extract}

The EA fraction was analyzed by HPLC to calculate oxyresveratrol content. A standard stock solution of oxyresveratrol was prepared at concentration $1 \mathrm{mg} / \mathrm{ml}$ in $80 \%$ ethanol and diluted into 5 different concentrations (from 0.0005 to $0.05 \mathrm{mg} / \mathrm{ml}$ ) to make calibration curve and to determine linear regression. The stock solution of the EA fraction was diluted in $80 \%$ ethanol. The HPLC analysis was used $\mathrm{C}_{18}$ bonded-silica gel column (YMC, $5 \mu \mathrm{m}, 150 \times 4.6 \mathrm{~mm}$, Phenomenex, Torrance, USA), the system (LC-20AT, Shimadzu, Kyoto, Japan) and equipped with a UV-Vis detector (SPD-20A, Shimadzu, Japan) in the isocratic mode. The mobile phase was used acetonitrile mixed with water in $1 \%$ acetic acid at ratio $1: 3$ with flow rate $1 \mathrm{ml} / \mathrm{min}$ and runtime set at $18 \mathrm{~min}$. UV detector wavelength was $320 \mathrm{~nm}$ and the injection volume was $20 \mu \mathrm{l}$ (Soonthornsit et al., 2017).

\section{RESULTS AND DISCUSSION}

This research was to investigate, firstly, the effect of IL structures which determine their physical and chemical properties on extracting analysis. The others were to investigate the effect of salting out on IL water solutions and to analyze TLC spots and HPLC chromatograms of EA fractions of IL-MAE extracts. IL 1butyl-3-methylimidazolium, as cation, with three kinds of anions, $\mathrm{Br}^{-}, \mathrm{BF}_{4}^{-}$, and $\mathrm{Cl}^{-}$, were studied by IL-MAE. The salting out using $\mathrm{Na}_{2} \mathrm{CO}_{3}$ and $\mathrm{KH}_{2} \mathrm{PO}_{4}$ with different concentration, $0.01,0.1,0.5$ and $1 \mathrm{M}$ and with no salt were determined.

\section{Thin layer chromatography (TLC) analysis}

ILs BmimBr, $\mathrm{BmimCl}$, and $\mathrm{BmimBF}_{4}$ were used to extract trans-oxyresveratrol from $M$. alba. TLC analysis was performed to compare the effect of the ionic liquids on the oxyresveratrol constituent in Morus alba root extract. EA fraction was observed under UV light at $366 \mathrm{~nm}$. Figure 1 showed the chromatogram of $1 \mathrm{mg} / \mathrm{ml}$ standard oxyresveratrol, EA fractions with $0.01 \mathrm{M} \mathrm{Na}_{2} \mathrm{CO}_{3}, 0.01 \mathrm{M} \mathrm{KH}_{2} \mathrm{PO}_{4}$, and without salt.

All sample showed oxyresveratrol spot at Rf 0.16 and, while standard at 0.17 . Densitometry under $254 \mathrm{~nm}$ resulted in 
AUC value of this spot and showed the amount of oxyresveratrol as seen in Table 1. The highest AUC showed the highest amount of oxyresveratrol. The salting out procedure was proposed to observe the separation of IL from the extract and to compare the amount of oxyresveratrol in EA fraction with and without salt addition. The result showed that salting out with $0.01 \mathrm{M} \mathrm{Na}_{2} \mathrm{CO}_{3}$ did not increase AUC values for ILs BmimBr and $\mathrm{BmimBF}_{4}$ than with no salt, while $0.01 \mathrm{M} \mathrm{KH}_{2} \mathrm{PO}_{4}$ increased AUC values significantly for all ILs. Fractionation with no salt showed $1.5 \mathrm{M}$ BmimBr have the highest AUC among another ILs, while with $\mathrm{Na}_{2} \mathrm{CO}_{3}, 1.67$ $\mathrm{M} \mathrm{BmimBF}_{4}$ showed the highest AUC, and $1.5 \mathrm{M} \mathrm{BmimCl}$ for $\mathrm{KH}_{2} \mathrm{PO}_{4}$ salt. This result showed that different ILs has a different optimum condition for extraction of oxyresveratrol from plant sample. From AUC values, it shows that the optimum IL and salting agent to extract oxyresveratrol from Morus alba root was $1.5 \mathrm{M} \mathrm{BmimCl}$ with $0.01 \mathrm{M} \mathrm{KH}_{2} \mathrm{PO}_{4}$ salt among another sample tested which AUC value 8736.1.

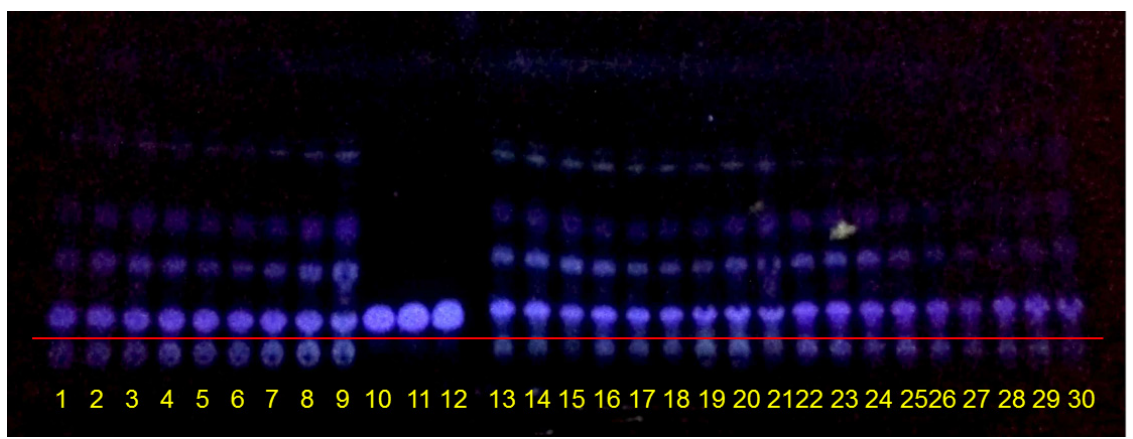

Fig. 1: TLC fingerprint analysis of Morus alba root extract under UV 366. From left to right, 1-3: 1.5, 1.67, 2 M BmimBr with 0.01 $\mathrm{M} \mathrm{KH}_{2} \mathrm{PO}$; 4-6: 1.5, 1.6, $2 \mathrm{M}$ BmimCl with $0.01 \mathrm{M} \mathrm{KH}_{2} \mathrm{PO}_{4}$; 7-9: 1.5, 1.6, $2 \mathrm{M} \mathrm{BmimBF}_{4}$ with $0.01 \mathrm{M} \mathrm{KH}_{2} \mathrm{PO}_{4}$; 11-12: standard oxyresveratrol; 13-15: 1.5, 1.67, $2 \mathrm{M} \mathrm{BmimBr}$ with no salt; 16-18: 1.5, 1.6, $2 \mathrm{M} \mathrm{BmimCl}$ with no salt; 19-21: 1.5, 1.67, $2 \mathrm{M} \mathrm{BmimBF}_{4}$ with no salt; 22-24: 1.5, 1.67, $2 \mathrm{M} \mathrm{BmimBr}$ with $0.01 \mathrm{M} \mathrm{Na}_{2} \mathrm{CO}_{3} ; 25-27: 1.5,1.6,2 \mathrm{M} \mathrm{BmimCl}$ with $0.01 \mathrm{M} \mathrm{Na}_{2} \mathrm{CO}_{3} ; 28-30: 1.5,1.67,2 \mathrm{M} \mathrm{BmimBF}_{4}$ with $0.01 \mathrm{M} \mathrm{KH}_{2} \mathrm{PO}_{4}$.

Table 1: AUC Value of Oxyresveratrol on Fractionation with Salt and No Salt Addition.

\begin{tabular}{|c|c|c|c|c|c|c|c|c|c|c|}
\hline \multirow{3}{*}{ IL } & \multirow{3}{*}{ Concentration (M) } & \multirow{3}{*}{ No Salt } & \multicolumn{8}{|c|}{ Salt } \\
\hline & & & \multicolumn{4}{|c|}{$\mathrm{Na}_{2} \mathrm{CO}_{3}$} & \multicolumn{4}{|c|}{$\mathrm{KH}_{2} \mathrm{PO}_{4}$} \\
\hline & & & $0.01 \mathrm{M}$ & $0.1 \mathrm{M}$ & $0.5 \mathrm{M}$ & $1 \mathrm{M}$ & $0.01 \mathrm{M}$ & $0.1 \mathrm{M}$ & $0.5 \mathrm{M}$ & $1 \mathrm{M}$ \\
\hline \multirow{3}{*}{$\mathrm{BmimBr}$} & 1.5 & 6341.6 & 5891.1 & 214.6 & 0 & 0 & 8374.8 & 7934.5 & 6552.5 & 6852.8 \\
\hline & 1.67 & 5800 & 6574.5 & 209.6 & 0 & 0 & 8570.8 & 7793.3 & 8502.9 & 8733.1 \\
\hline & 2 & 4472.7 & 4761.8 & 0 & 0 & 0 & 8103.6 & 7357.1 & 6956.6 & 7877.4 \\
\hline \multirow{3}{*}{$\mathrm{BmimCl}$} & 1.5 & 5563.9 & 5339.4 & 498.3 & 444.2 & 0 & 8736.1 & 7177.6 & 6561.6 & 6903.4 \\
\hline & 1.67 & 4993 & 4490.8 & 469.4 & 318.3 & 0 & 7660.5 & 7993.1 & 7015.9 & 7882.5 \\
\hline & 2 & 4716.8 & 2828.7 & 389.6 & 265.3 & 295.6 & 6197.6 & 6607.7 & 5873.8 & 5820.2 \\
\hline \multirow{3}{*}{$\mathrm{BmimBF}_{4}$} & 1.5 & 4629.8 & 6742.6 & 6759.3 & 905.4 & 942.3 & 7044.6 & 7399.6 & 806.5 & 7990.7 \\
\hline & 1.67 & 6092.8 & 8652.7 & 6132.5 & 919 & 1016.1 & 7700.8 & 6930 & 783.5 & 4918.9 \\
\hline & 2 & 5060.4 & 7348 & 4851.2 & 979.1 & 1489.3 & 7907.3 & 5362.5 & 588.6 & 6143.6 \\
\hline
\end{tabular}

Compared the results of three ILs, with the same cation at the same concentration $(1.5 \mathrm{M})$ where analyzed by TLCdensitometry, salting out with $0.01 \mathrm{M} \mathrm{Na}_{2} \mathrm{CO}_{3}$ did not increase AUC values for ILs BmimBr and $\mathrm{BmimBF}_{4}$ than with no salt, while $0.01 \mathrm{M} \mathrm{KH}_{2} \mathrm{PO}_{4}$ increased AUC values significantly for all ILs. This means that $\mathrm{Na}_{2} \mathrm{CO}_{3}$ cannot separate oxyresveratrol optimally from IL solution, while $\mathrm{KH}_{2} \mathrm{PO}_{4}$ salt successfully interacts and increases the separation. Fractionation with no salt showed $1.5 \mathrm{M}$ BmimBr have the highest AUC among another ILs, while with $\mathrm{Na}_{2} \mathrm{CO}_{3}, 1.67 \mathrm{M} \mathrm{BmimBF}_{4}$ showed the highest AUC, and $1.5 \mathrm{M}$ $\mathrm{BmimCl}$ for $\mathrm{KH}_{2} \mathrm{PO}_{4}$ salt. This result showed that different ILs has a different optimum condition for extraction of oxyresveratrol from plant sample.

The solution of ILs in water could greatly enhance the extraction yields of oxyresveratrol from $M$. alba roots. These can be explained that ILs had high solvation power and interactions with oxyresveratrol that contribute to raising the solubility of oxyresveratrol. That interactions influence by physical structures and chemical bonds, especially hydrogen bonding, polarity, $\pi-\pi$, and ionic/charge-charge. Therefore, the characteristic of ionic liquids to influence the conformation of carbohydrates through hydrogen bonding and can be considered as viable substituents to be value-added solvents. On the other hand, ILs can absorb and transfer microwave energy efficiently and consequently make the solvent and the sample warming rapidly. Both of them improved the efficiency of oxyresveratrol extraction from $M$. alba roots (Zeng et al., 2010; Ahmad et al., 2017).

The concentration of salt also influences the separation ability, where salts $\left(\mathrm{Na}_{2} \mathrm{CO}_{3}\right.$ and $\left.\mathrm{K}_{2} \mathrm{HPO}_{4}\right)$ at concentration 0.01 $\mathrm{M}$ give AUC higher than at concentration $0.1,0.5$, and $1 \mathrm{M}$. The 
previous study, at separation IL solution, $0.01 \mathrm{M} \mathrm{Na}_{2} \mathrm{CO}_{3}$ had the best result to obtain trans-resveratrol among the other, whereas the $\mathrm{K}_{2} \mathrm{HPO}_{4}$ had no ability on separation trans-resveratrol from the IL solution (Ayuningtyas et al., 2017). This showed that salt added at low concentration help to enhance separation of ionic liquid and recovery of chemical compounds from crude extract. On other works, IL-MAE with the addition of $\mathrm{KH}_{2} \mathrm{PO}_{4}$ salt obtained gamma oryzanol higher than $\mathrm{Na}_{2} \mathrm{CO}_{3}$ salt and without salt which is caused by the interaction of solutes (ion of inorganic salts and ionic liquid) and solvents (Trinovita et al., 2017).

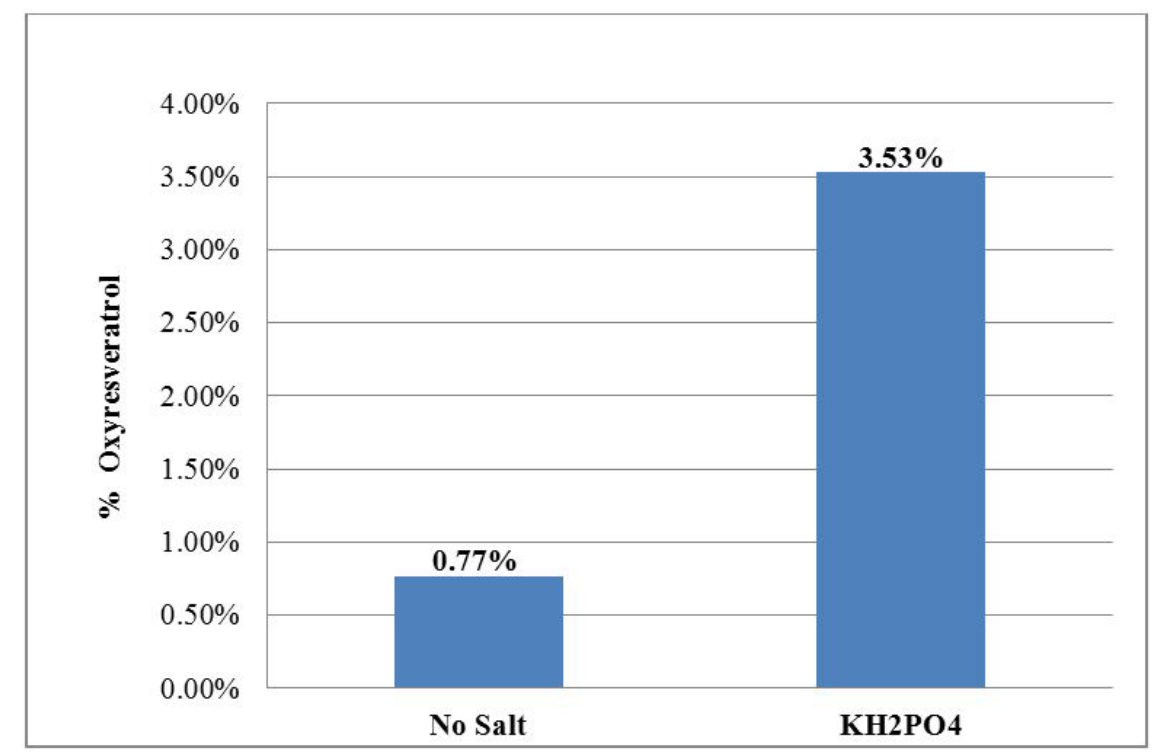

Fig. 2: The yield of oxyresveratrol obtained by $1.5 \mathrm{M} \mathrm{BmimCl}$ EA fractions with $0.01 \mathrm{M} \mathrm{KH}_{2} \mathrm{PO}_{4}$ salt and no salt addition.

Table 2: Percentage of Oxyresveratrol from Morus alba using Different Extraction Methods.

\begin{tabular}{|c|c|c|c|c|c|c|}
\hline No & Methods & Sample & Extract yield & Fraction yield & Oxyresveratrol (w/w) & Reference \\
\hline 1 & Methanol & Branch & $5.8 \%$ & $1.89 \%$ & & Chen et al., 2013 \\
\hline 2 & Methanol & Barks, Roots & & & $0.26 \%, 0.27 \%$ & Ayinampudi et al., 2011 \\
\hline 3 & Ethanol & Stems & $5.13 \%$ & & $17.87 \pm 0.61 \%$ & Zeng et al., 2010 \\
\hline 4 & IL-MAE & Roots & & $3.53 \%$ & $79.5 \%$ & \\
\hline
\end{tabular}

\section{Separation of oxyresveratrol}

This study showed that the highest oxyresveratrol was separated from $1.5 \mathrm{M} \mathrm{BmimCl}$ with $0.01 \mathrm{M} \mathrm{KH}_{2} \mathrm{PO}_{4}$ salt with EA fractionation and was repeated four times and compared with the solution without salt, then calculated. The yield of EA fraction from solution with salt and without salt was $3.53 \%$ and $0.77 \%$ from 10-gram raw material respectively as shown in Figure 2.

\section{High-performance liquid chromatography (HPLC) analysis of oxyresveratrol in the extract}

The amount of oxyresveratrol of EA fraction determined and analyzed by HPLC. EA fraction of BmimCl IL-MAE and a standard solution of oxyresveratrol were diluted in $80 \%$ ethanol and were analyzed under $320 \mathrm{~nm}$. The chromatograms of EA fraction were compared with standard oxyresveratrol as shown in Figure 3. A series of standard oxyresveratrol solutions at five concentration range from 0.05 to $0.0005 \mathrm{mg} / \mathrm{ml}$ were prepared to make calibration curve and determine the linearity of this method for analyzing oxyresveratrol in $M$. alba roots. The calibration curve, as seen in Figure 4, showed regression linear by $\mathrm{y}=$ $94383016 x+36277$ and regression coefficients $(r)=0.99949$. The calculated amount of oxyresveratrol from $1.5 \mathrm{M} \mathrm{BmimCl}$ (ILMAE method) with $0.01 \mathrm{M} \mathrm{KH}_{2} \mathrm{PO}_{4}$ salt was $60.212 \mu \mathrm{g} / \mathrm{ml}$ with yield $79.5 \%$.

While previous studies, on trans-resveratrol content has been extracted from optimum IL-MAE condition $2.5 \mathrm{M} \mathrm{BmimBr}$ solution, $15 \mathrm{~mL} / \mathrm{g}$ liquid/solid ratio, 10\% microwave power, and 10 min extraction time (Ayuningtyas et al., 2017), on the yield of total polyphenolics content, IL-MAE $0.7 \mathrm{M} \mathrm{BmimCl} \mathrm{(14}$ $\mathrm{ml} / 1$ liquid-solid ratio, and 270 Watts microwave power for 10 minutes) better than $0.7 \mathrm{M} \mathrm{BmimBr}(14 \mathrm{ml} / 1$ liquid-solid ratio, and 270 Watts microwave power for 15 minutes) (Ahmad et al., 2017).

This result was compared with the previous study of oxyresveratrol extraction on literature, as seen in Table 2 EA fraction of M. alba branch yield was $1.89 \%$ (Chen et al., 2013). Oxyresveratrol from barks and roots methanolic extract calculated with HPTLC method was $0.27 \%$, and $0.30 \%$, and was not identified in leaves, fruits, or xylem (Ayinampudi et al., 2011) and from stems ethanolic extract calculated with HPLC was $17.87 \pm$ $0.61 \%$ with yield $5.13 \%$ (Zeng et al., 2010).

The efficiency of the IL-MAE method was much higher than the maceration method that caused damage to the cell wall surface of the sample matrix by microwave irradiation interference (Ahmad et al., 2017). IL-MAE method and salting out an improved yield of oxyresveratrol from $M$. alba roots significantly. 


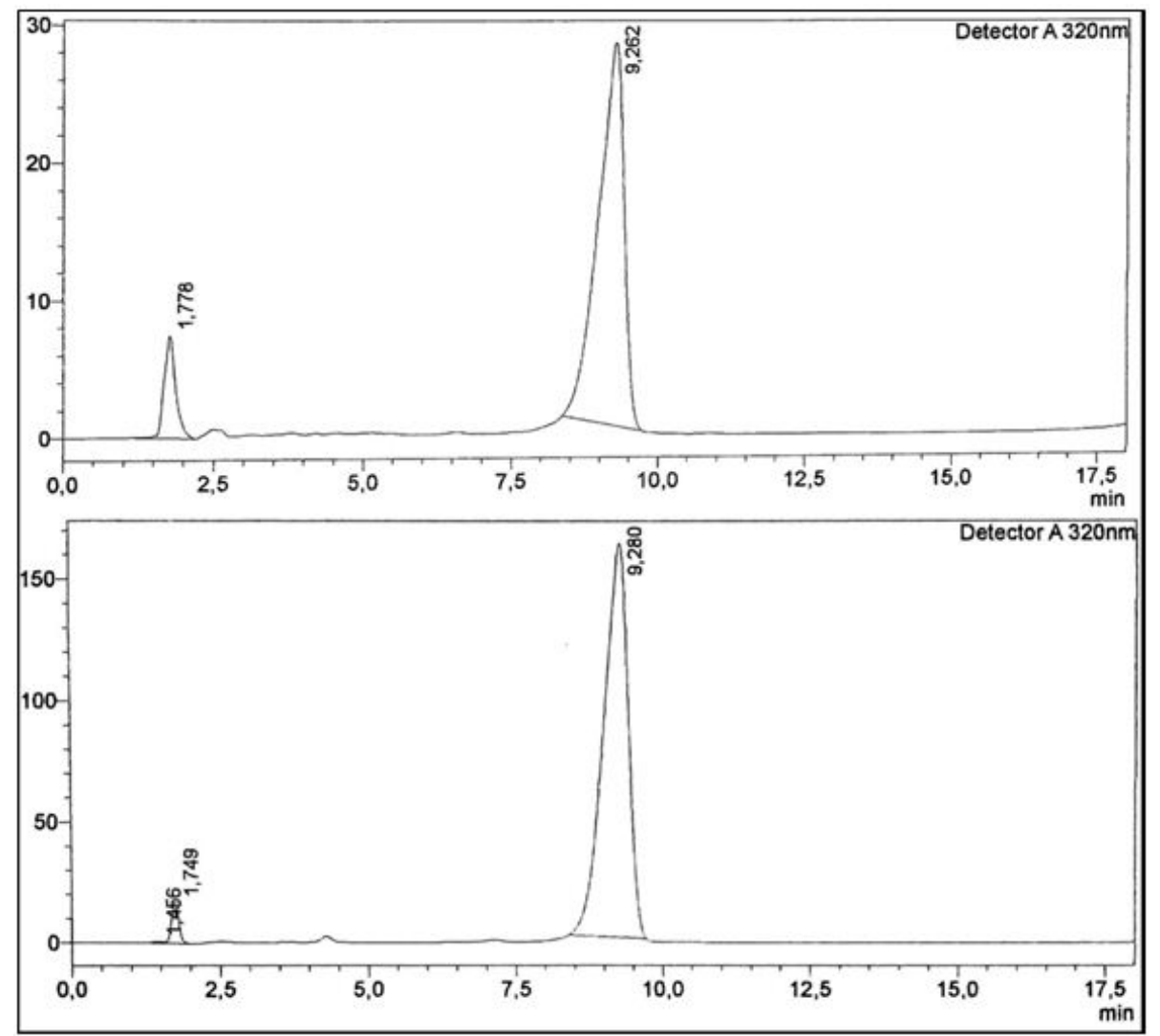

Fig. 3: HPLC chromatograms of EA fraction of IL-MAE root extract (above) and standard oxyresveratrol (below) $50 \mathrm{ppm}$ under detection of $320 \mathrm{~nm}$.

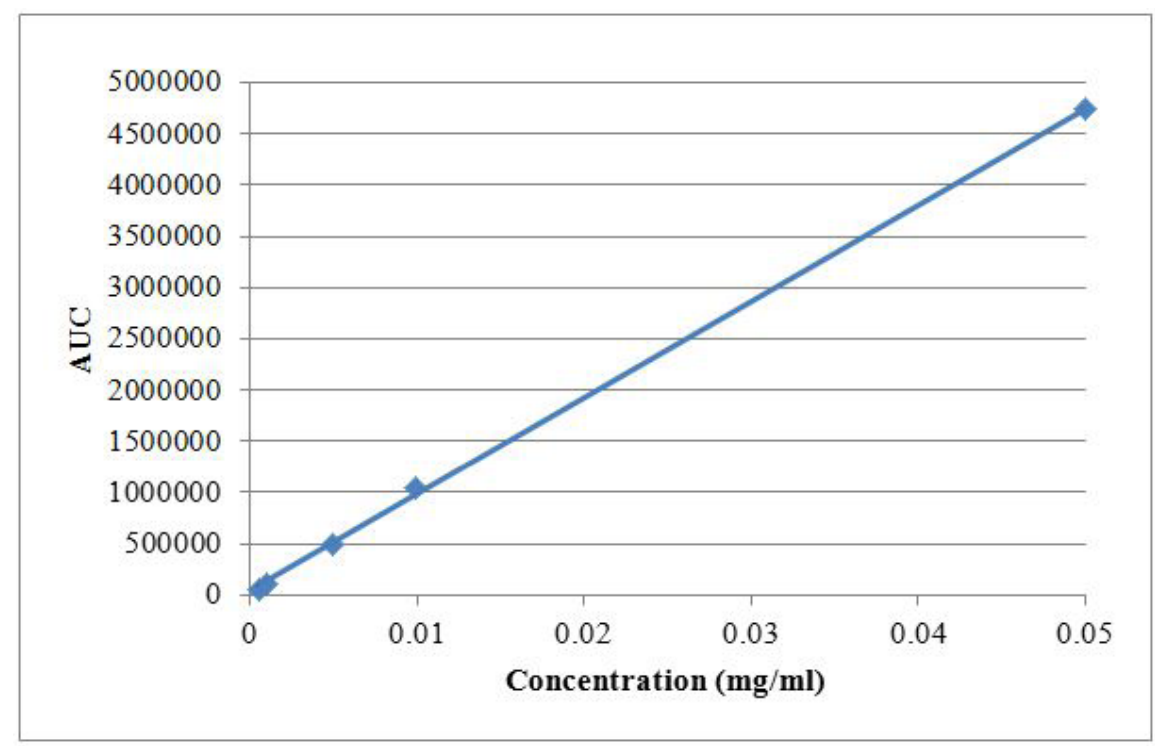

Fig. 4: Calibration curve of oxyresveratrol.

\section{CONCLUSION}

Ionic liquid-based microwave-assisted extraction (ILMAE) would be an option to extract oxyresveratrol from Morus alba compared with the ethanolic and methanolic maceration. This research showed the optimum condition of IL-MAE to extract oxyresveratrol from $M$. alba root was $1.5 \mathrm{M} \mathrm{BmimCl}$ with $0.01 \mathrm{M}$
$\mathrm{KH}_{2} \mathrm{PO}_{4}$ salt solution. The adding salt improved extraction yield of EA fraction of $M$. alba roots from $0.77 \%$ to $3.53 \%$. The calculated oxyresveratrol from EA fraction was $79.5 \%$.

\section{ACKNOWLEDGMENT}

This study was supported by Universitas Indonesia for Hibah PITTA 2017. 


\section{CONFLICT OF INTEREST}

The authors have no conflict of interest to declare.

\section{ABBREVIATIONS}

$\begin{array}{ll}\text { AUC: } & \text { Area Under Curve } \\ \text { BmimCl: } & \text { 1-butyl-3-methylimidazolium chloride } \\ \text { BmimBr: } & \text { 1- butyl-3-methylimidazolium bromide } \\ \mathrm{BmimBF}_{4}: & \text { 1-butyl-3-methylimidazolium tetrafluoroborate } \\ \mathrm{EA}: & \text { ethyl acetate } \\ \mathrm{HPLC}: & \text { High performance liquid chromatography } \\ \mathrm{KH}_{2} \mathrm{PO}_{4}: & \text { Potassium dihydrophosphate } \\ \mathrm{IL}: & \text { Ionic Liquid } \\ \mathrm{IL}-\mathrm{MAE}: & \begin{array}{l}\text { Ionic Liquid-based Microwave Assisted } \\ \text { Extraction }\end{array} \\ \mathrm{MAE}:_{\mathrm{Na}} \mathrm{CO}_{3}: & \text { Microwave Assisted Extraction } \\ \mathrm{TLC}: & \text { Thin Layer Chromatography. }\end{array}$

\section{REFERENCES}

Ahmad I, Yanuar A, Mulia K, Mun'im A. Application of Ionic Liquid as a Green Solvent for Polyphenolics Content Extraction of Peperomia pellucida (L) Kunth Herb. J Young Pharm, 2017; 9(4):486-90. Ayinampudi SR, Wang Y, Avula B, Smillie TJ, Khan IA Quantitative Analysis of Oxyresveratrol in Different Plant Parts of Morus Species and Related Genera by HPTLC and HPLC. JPC, 2011; 24:125-9.

Ayuningtyas IN, Rahmawati M, Sutriyo, Mun'im A. Optimization of Ionic Liquid-Based Microwave Assisted Extraction to Obtain Transresveratrol from Gnetum gnemon. J Young Pharm, 2017; 9(4):446-51.

Chan EW, Lye P, Wong S. Phytochemistry, pharmacology, and clinical trials of Morus alba. Chi J Nat Med, 2016; 14:17-30.
Chen Y, Tien Y, Chen C, Beltran FN, Amor EC, Wang R. Morus alba and active compound oxyresveratrol exert anti-inflammatory activity via inhibition of leukocyte migration involving MEK / ERK signaling. BMC Comp and Alt Med, 2013; 13:45.

$\mathrm{Du}$ F, Xiao X, Li G. Application of ionic liquids in the microwave-assisted extraction of trans-resveratrol from Rhizoma Polygoni Cuspidati. J Chroma, 2007; 1140:56-62.

Han D, Row KH. Recent Applications of Ionic Liquids in Separation Technology. Mol, 2010; 15:2405-26.

Justyna P, Owczarek K, Tobiszewski M, Namie. Extraction with Environmentally Friendly Solvents. J Tre Analy Chem, 2017; 91:12-25.

Kim YM, Yun J, Lee C, Lee H, Min KR, Kim Y. Oxyresveratrol and hydroxystilbene compounds: inhibitory effect on tyrosinase and mechanism of action. J Biol Chem, 2002; 277:16340-4.

Shin NH, Ryu SY, Choi EJ, Kang SH, Chang IM, Min KR, Kim Y. Oxyresveratrol as the potent inhibitor of dopa oxidase activity of mushroom tyrosinase. J Biochem Bioph Res Commun, 1998; 243:801-3.

Soonthornsit N, Pitaksutheepong C, Hemstapat W, Utaisincharoen P, Pitaksuteepong T. In Vitro Anti-Inflammatory Activity of Morus alba L. Stem Extract in LPS-Stimulated RAW 264.7 Cells. EvidBased Comp and Alt Med, 2017; 2017: Article ID 3928956.

Trinovita E, Saputri FC, Mun'im A. Enrichment of the Gamma Oryzanol Level from Rice Bran by Addition of Inorganic Salts on Ionic Liquid 1-Butyl-3-Methylimidazolium Hexafluorophosphate ([BMIM]PF $)$ Extraction. J Young Pharm, 2017; 9(4):555-8.

Vekariya RL. A review of ionic liquids: Applications Towards Catalytic Organic Transformations. J Mol Liq, 2017; 227:44-60.

Zeng $\mathrm{H}$, Wang Y, Kong J, Nie C, Yuan Y. Ionic liquid-based microwave-assisted extraction of rutin from Chinese medicinal plants. Talanta, 2010; 83:582-90.

How to cite this article:

Fadhila M, Mun'im A, Jufri M. Ionic Liquid-based MicrowaveAssisted Extraction (Il-MAE) of Oxyresveratrol from Morus alba Roots. J App Pharm Sci, 2018; 8(06): 008-013. 